Research Article

\title{
Gastroprotective Activity of the Total Flavones from Abelmoschus manihot (L.) Medic Flowers
}

\author{
Jun Zhang $\mathbb{D}^{1,2}$ Zai-Lin Fu ${ }^{10},{ }^{3}$ Zhao-Xing Chu, ${ }^{4}$ and Bi-Wei Song ${ }^{2}$ \\ ${ }^{1}$ Department of Pharmacy, The Second Affiliated Hospital of Zhejiang Chinese Medicine University, Hangzhou, \\ Zhejiang 310005, China \\ ${ }^{2}$ Institute of Pharmacology, Zhejiang University of Technology, Hangzhou, Zhejiang 310014, China \\ ${ }^{3}$ Department of Pharmacy, First People's Hospital of Yuhang District, Hangzhou, Zhejiang 311100, China \\ ${ }^{4}$ China Pharmaceutical University, Nanjing, Jiangsu 210009, China
}

Correspondence should be addressed to Zai-Lin Fu; fuzailin@163.com

Received 4 July 2019; Accepted 4 January 2020; Published 25 February 2020

Academic Editor: George B. Lenon

Copyright (c) 2020 Jun Zhang et al. This is an open access article distributed under the Creative Commons Attribution License, which permits unrestricted use, distribution, and reproduction in any medium, provided the original work is properly cited.

Background. Abelmoschus manihot (L.) Medic flower is a medicinal plant for the treatment of diseases in China. The present study was carried out to scientifically validate the gastroprotective activity and clarify the possible mechanism of the total flavones from Abelmoschus manihot (L.) Medic flowers (TFA). Methods. Gastric ulcer was induced in mice by oral administration of ethanol. The gastroprotective activity of TFA was evaluated by the gastric ulcer index and histological examinations. The gastric tissue was collected in the form of homogenate. The level of malondialdehyde (MDA) and glutathione (GSH), the activity of superoxide dismutase (SOD), and protein content were measured. Western blotting for the expression of Bax, Bcl-2, TNF- $\alpha$, and NF- $\kappa \mathrm{B}(\mathrm{p} 65)$ was also carried out. The effect of TFA was compared with that of standard antiulcer drug omeprazole $(100 \mathrm{mg} / \mathrm{kg})$. Results. This gastroprotective effect of TFA could be attributed to the increase in the activity of SOD and GSH and decrease in the levels of MDA and also decrease in the levels of Bax, TNF- $\alpha$, and NF- $\kappa \mathrm{B}(\mathrm{p} 65)$ expressions and increase in the Bcl- 2 expression level. Conclusion. The findings of this study demonstrated that TFA could significantly attenuate ethanol-induced gastric injury via antioxidative, anti-inflammatory, and antiapoptotic effects.

\section{Background}

Gastric ulcer is a common digestive disease with an increasing incidence and prevalence attributed to the loss of balance between aggressive and protective factors [1]. There is about $10 \%$ of the world's population suffering from the gastric ulcer [2]. The most common presenting symptom of patients with the gastric ulcer is often characterized with burning or gnawing pain in the center of the abdomen [3].

The etiology of the gastric ulcer is multifactorial, including alcohol abuse, stress, smoking, nonsteroidal anti-inflammatory drugs overuse, and Helicobacter pylori infection $[4,5]$. Excessive alcohol consumption is a major reported causesr cause for gastric ulcer [6]. Alcohol, as an ulcerogenic substance, can perturb the gastric mucosa and induce metabolic disorders, leading to inflammation, hyperemia, edema, hemorrhage, and erosive lesions [7]. Alcohol also markedly increases the accumulation of free radical oxygen and lipid peroxidation and synchronously suppresses the activity of antioxidant enzymes such as superoxide dismutase and glutathione peroxidase in the gastric tissues, which promotes the necrosis and apoptosis of gastric epithelial cells [8]. Thus, alcohol is commonly used to induce experimental gastric ulcer models in animals [9]. Most of the existing antiulcer drugs mainly work via the manner of acid suppression and indirectly promote the self-healing of gastric mucosa, but show limited efficacy [10]. Lots of clinical and experimental studies have demonstrated that utilization of herbal medicines could be a valuable alternative to cure the gastric ulcer with few adverse effects [11].

Abelmoschus manihot (L.) Medic is a medicinal plant which belongs to the family of Malvaceae. It is widely 
distributed in Papua New Guinea, New Caledonia, and China [12]. As a folk medicine in Eastern Europe and Asia, its flower has been used for a variety of purposes for hundreds of years [13]. Pharmacological researches have demonstrated that the extractive of its flowers has a wide range of pharmacological activities, including analgesic, anti-inflammory, antioxidant, hepatoprotective, renal protection, and cardiovascular protection [14]. The extensive phytochemical and pharmacological studies have indicated that total flavonoids extracted from flowers of Abelmoschus manihot (L.) Medic (TFA) were the major bioactive compounds in the extractive $[15,16]$. However, no systematic study has been carried out on TFA to verify for the gastroprotective activity yet. Thus, this work was undertaken to investigate and validate the protection effect of TFA on gastric ulcer in mice and its possible mechanism of action.

\section{Materials and Methods}

2.1. Drugs and Reagents. Omeprazole was purchased from AstraZeneca Pharmaceutical Co., Ltd. (London, UK). GSH, MDA, and SOD kits were provided by Jiancheng Bioengineering Institute (Nanjing, China). GAPDH antibody, Bcl-2, Bax, NF- $\kappa \mathrm{B}$ p65, and HRP-conjugated secondary antibody were purchased from Boster (Wuhan, China). TNF- $\alpha$ antibody was provided by Proteintech Group Inc. (Chicago, USA). Hyperoside standard was provided by Anhui Institute of Medical Science. All other chemicals were of analyticalreagent grade with the highest quality commercially available.

2.2. Plant Material and TFA Preparation. The dried flowers of Abelmoschus manihot (L.) Medic were purchased from the wholesale market of Chinese Herbals in Bozhou, Anhui Province. The flowers were identified by Prof. Song Biwei (College of Pharmaceutical Sciences, Zhejiang University of Technology). A voucher specimen was deposited in the Herbarium of the Department of Pharmacology of the College of Pharmaceutical Sciences, Zhejiang University of Technology.

The TFA was extracted from the flowers of Abelmoschus Manihot (L.) Medic by the Department of Pharamcology, Zhejiang University of Technology, Zhejiang, China. The dried flowers were shredded in an electric mill. Powdered Abelmoschus Manihot (L.) Medic flowers were immersed in $70 \%$ ethanol (v/v). The mixture was extracted 3 times under reflux for $0.5 \mathrm{~h}$. Then, the decoction was filtered through the analytical filter paper and evaporated by rotary evaporation under vacuum at $40^{\circ} \mathrm{C}$. The "drug extract" ratio of Abelmoschus manihot ethanolic extract was $1: 1(1 \mathrm{~g} / \mathrm{mL})$. The main active components of TFA were hyperoside, isoquercitrin, hibifolin, quercetin-30-O-glycoside, quercetin, myricetin, and rutin [13].

2.3. Total Flavonoids Content Determination. Total flavonoids content of the decoction was determined by the Acetic Acid-Sodium Acetate-Aluminum Chloride method with some modifications [17]. Briefly, the decoction was diluted to $25 \mathrm{~mL}$ using $70 \%$ ethanol. $1 \mathrm{ml}$ of the diluted ethanolic extract was transferred to a $25 \mathrm{~mL}$ volumetric flask. $5 \mathrm{~mL}$ of Acetic Acid-Sodium Acetate buffer (2 M Acetic Acid: $2 \mathrm{M}$ Sodium Acetate buffer $=3: 1$ ) was added to the mixture followed by adding $3 \mathrm{~mL}$ of $0.1 \mathrm{M}$ Aluminum Chloride solution. The final volume was adjusted to $25 \mathrm{ml}$ by ultrapure water. The mixture was incubated at room temperature for $40 \mathrm{~min}$, and the absorbances of the mixture were measured in $401 \mathrm{~nm}$. The standard hyperoside curve was used to calculate total flavonoid content. The analysis was performed in triplicate.

2.4. Hyperoside Content Determination by HPLC. Samples for HPLC were prepared from the decoction. $0.5 \mathrm{~mL}$ of the TFA was transferred to a $25 \mathrm{~mL}$ volumetric flask. The solutions were diluted to $25 \mathrm{~mL}$ by HPLC grade methanol. They were filtered through a $0.2 \mu \mathrm{m}$ syringe filter. Reference standard hyperoside was prepared by weighing $0.1 \mathrm{mg} / \mathrm{ml}$ of hyperoside. A Hitach L2000 series HPLC system (Hitach, Tokyo, Japan) was used to analyze hyperoside in this experiment. The analytical column used was a $250 \mathrm{~mm} \times 4.6 \mathrm{~mm}$ i.d. HITACHI LaChrom C18 $(5 \mu \mathrm{m})$ maintained at $30^{\circ} \mathrm{C}$. The flow rate was kept at $1 \mathrm{ml} / \mathrm{min}$, and the injection volume was $10 \mu \mathrm{L}$. Two solvents, A (acetonitrile) and B ( $0.1 \%$ phosphoric acid) were used for elution of constituents. The elution of the mobile phase can be described as follows: $(\mathrm{A}) /(\mathrm{B})=10 / 90(0 \mathrm{~min}) \longrightarrow$ 20/80 (20 30 min) $\longrightarrow$ 25/75 (30 40 min) $\longrightarrow 30 / 70(40 \sim$ $45 \mathrm{~min}) \longrightarrow 15 / 85 \quad(45 \sim 50 \mathrm{~min}) \longrightarrow 10 / 90 \quad(50 \sim 60 \mathrm{~min})$. The chromatogram peaks were detected at $360 \mathrm{~nm}$ [18].

2.5. Experimental Animals. The experiments were carried out on healthy ICR mice (18-22 g, 6-8 weeks) of either sex. They were obtained from Zhejiang Academy of Medical Sciences (License no. SCXK 2014-0001). All mice were kept in standardized animal house at $25 \pm 2^{\circ} \mathrm{C}$, light and dark cycles of 12/12 hours, respectively. A balanced diet and free access of water were provided. They were starved for 24 hours before use though water was allowed ad libitum. The mice were cared for in accordance with the "Principles of laboratory animal care" (NIH publication no. 82-23, revised 1996) guidelines. The experiments were designed according to the Institutional Animal Ethical Committee.

2.6. Ethanol-Induced Gastric Ulcer Model. The experiment was carried out according to the method of Hollander et al. with a few modifications [19]. The mice were randomly divided into 6 groups of 10 mice each: control group, model group, omeprazole group (100 mg/kg), and TFA group (300, 600 , and $1200 \mathrm{mg} / \mathrm{kg}$ ). They were all gavaged with $0.4 \mathrm{~mL}$ absolute alcohol except the control group. The same volumes of sterile water were gavaged to the mice of the control group. 1 hour later, sterile water, omeprazole, or TFA was administrated to each group. After 4 hours, they were sacrificed by cervical dislocation.

2.7. Determination of Ulcer Index and Percentage of Inhibition. The isolated stomachs were immediately fixed with $4 \%$ paraformaldehyde for 20 minutes. Then they were opened 
along the greater curvature and washed with saline solution $(0.9 \% \mathrm{NaCl})$. The inner surface of the stomachs was examined for ulceration with the help of a dissecting microscope. The ulcer index (UI) was calculated as described by the method of Guth [20]. The percentage of inhibition was calculated by the following formula [21]:

$$
\left[\frac{(\text { UIcontrol - UItreated })}{\text { UIcontrol }}\right] \times 100 \text {. }
$$

2.8. Biochemical Estimation. The tissues from stomachs were cut into pieces. The weight of each one was then recorded. The samples were homogenized in 9 volumes of cold saline solution. The homogenates were centrifuged at $10000 \mathrm{~g}$ for $20 \mathrm{~min}$ at $4^{\circ} \mathrm{C}$. The supernatants were used to determine the biochemical parameters. The concentration of total protein in the supernatants was measured by the BCA protein assay kit (Boster, Wuhan, Hubei, China). Levels of GSH, MDA, and SOD were determined by the commercial assay kits according to the manufacturer's instructions (Jiancheng Bioengineering Institute, Nanjing, China) for users.

2.9. Histopathological Evaluation. One part of the stomachs was fixed in $4 \%$ paraformaldehyde solution for 24 hours. Then, they were embedded in paraffin wax. The $5 \mu \mathrm{m}$ thickness tissue sections were repaired and stained with hematoxylin and eosin (HE). The slides were examined under light microscope to observe the morphological changes and recorded.

2.10. Western Blotting. Gastric tissues were cut into pieces and homogenized with ice-cold cell lysis buffer for western blotting and an IP kit (Beyotime, shanghai, China) for $30 \mathrm{~min}$ at $4^{\circ} \mathrm{C}$. The homogenates were centrifuged at $14000 \mathrm{~g}$ for $10 \mathrm{~min}$ at $4^{\circ} \mathrm{C}$. Then, the supernatants were collected and the concentrations of total protein were detected by a BCA protein assay kit (Boster, Wuhan, Hubei, China). Equivalent amounts of proteins were separated by electrophoresis on $12 \%$ and $5 \%$ sodium dodecylsulfate (SDS) polyacrylamide gels (SDS-PAGE) and transferred to nitrocellulose membranes (Beyotime, shanghai, China). The membranes were blocked with $5 \% \mathrm{BSA}$ at room temperature for 2 hours. The blots were incubated overnight at $4^{\circ} \mathrm{C}$ with primary antibodies against TNF- $\alpha$ ( $1: 1000$, Proteintech Group Inc, Chicago, USA), Bax, Bcl-2, GAPDH, and NF- $\kappa$ B p65 (1:200, Boster, Wuhan, China). After washing, the membranes were incubated with the appropriate HRP-conjugated secondary antibodies (Boster, Wuhan, Hubei, China) for 2 hours at room temperature. Photodensity analysis was utilized with the chemiluminescence detection system (Bio-Rad, Hercules, CA, USA) after visualizing by HRP substrate ECL solution (Boster, Wuhan, China).

2.11. Statistic Analysis. The results of the experiments were presented as mean $\pm S D$, and one-way analysis of variance (ANOVA) was used to analyze comparison in different groups. $p<0.05$ was considered to be significant. Data analysis was achieved using the software progam GraphPad Prism 5.

\section{Results}

3.1. Total Flavonoids Content. After making a standard calibration curve by hyperoside $(y=0.0246 x-0.0023$, $\left.r^{2}=0.9999\right)$, the total flavonoids content of the TFA was found to be $(4.68 \pm 0.07) \%(w / w)$, respectively.

3.2. Hyperoside Content. The standard calibration curve of hyperoside was used to evaluate the content of flavonoid in the extract. The hyperoside content of the TFA was $(1.14 \pm 0.27) \%(\mathrm{w} / \mathrm{w})$, respectively (Figure 1$)$.

3.3. Effect of TFA on the Ulcer Index and Percentage of Inhibition. Ethanol is regarded as one of the major risk factors for the pathogenesis of gastric ulcer. A representative stomach of each group is shown in Figure 2. The model group presented severe mucosal injury (ulcer index: $41.10+18.28)$. TFA could significantly increase the inhibition rate of ethanol-induced gastric ulcer at the dose of 600 and $1200 \mathrm{mg} / \mathrm{kg}$ (Table 1). Compared with the positive control group, TFA showed better results than omeprazole. The effect of TFA was in a dose-dependent manner, of which the high-dose group reached the maximum $66.91 \%$ inhibition rate $(p<0.001)$.

3.4. Effect of TFA on Biochemical Parameters. All the results are shown in Figures 3(a)-3(c)). Ethanol caused a marked significant increase in the levels of MDA $(p<0.001)$ and reduction in the activities of SOD $(p<0.001)$ and GSH levels $(p<0.001)$ in ulcerated mice as compared to the control group. Contrarily, TFA $(600 \mathrm{mg} / \mathrm{kg})$ and TFA $(1200 \mathrm{mg} / \mathrm{kg})$ treatments dramatically decreased MDA levels in gastric tissue with a concomitant increase in the activities of SOD and GSH levels as compared with the model group, especially the high-dose group.

3.5. Histologic Evaluations of Gastric Tissue. The gastric tissue specimens of different groups were observed under a microscope, and the pathological changes are shown in Figures 4 and 5. In the control group, the structure of the gastric tissue was intact and the epithelial cells were tightly arranged (Figures 4(a), 5(a)). However, there were various histopathological alterations including congestion, cellcontained hyperaemia and edema, gastric epithelial cells necrosis, inflammatory changes, and erosions in the gastric tissue of model group mice (Figures 4(b), 5(b)). Compared with the model group, this poor sanitation was restrained by TFA or Omeprazole, and the structure was tended to be normal. The results suggested that TFA could reduce gastric mucosa injury induced by ethanol. 


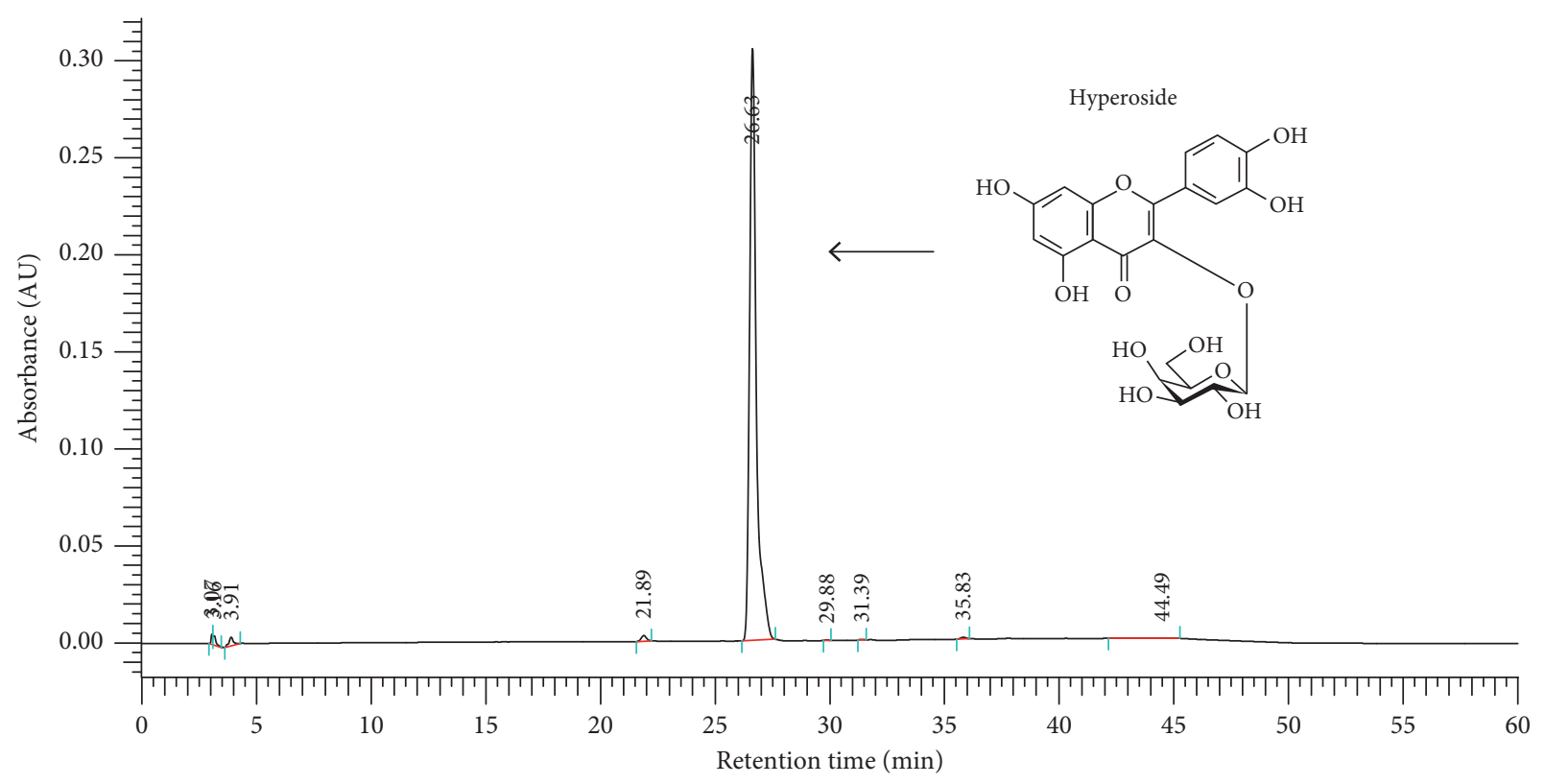

(a)

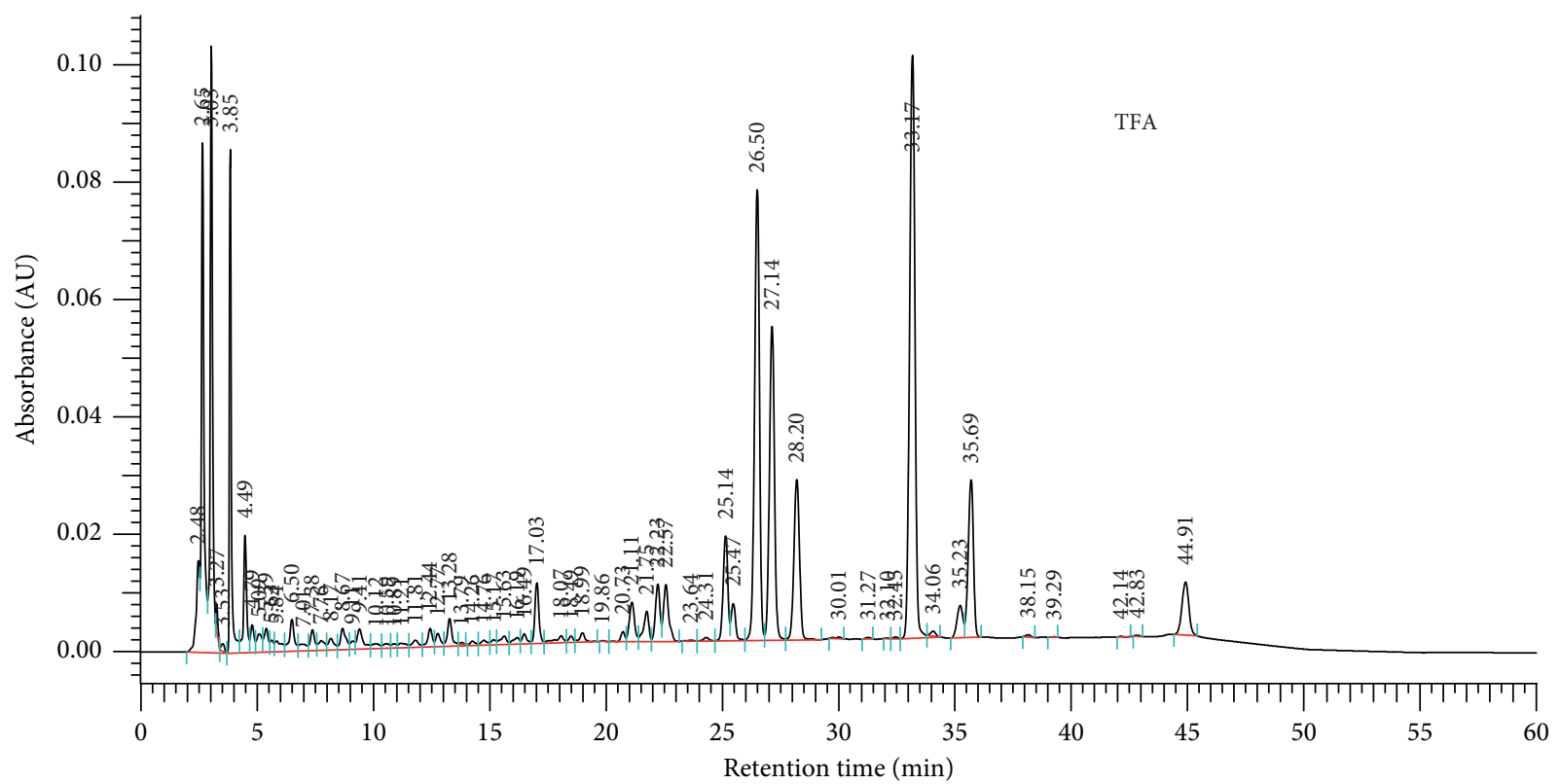

(b)

FIgURE 1: HPLC profile of hyperoside and TFA.

\subsection{The Expression of Proteins in the Gastric Tissue}

3.6.1. Effect of TFA on the Expression of Bax and Bcl-2. The results of Bax and Bcl-2 protein expression were shown in Figures 6 and 7. The expression of the proapoptotic factor Bax in the model group was significantly higher than the control group $(p<0.001), 1.87$ folds higher than the control group, and the expression of the antiapoptotic factor Bcl-2 was significantly lower $(p<0.001), 62 \%$ of the control group. The ratio of $\mathrm{Bax} / \mathrm{Bcl}-2$ in the each treatment group was significantly lower than that in the model group, especially in the TFA high-dose group. This results demonstrated that
TFA can downregulate the expression of Bax, upregulate the expression of $\mathrm{Bcl}-2$, and thus decrease the ratio of $\mathrm{Bax} / \mathrm{Bcl}-2$ to inhibit the activation of the endogenous apoptotic pathway.

3.6.2. Effect of TFA on the Expression of TNF- $\alpha, N F-\kappa B p 65$. The results of the expression of TNF- $\alpha$ and NF- $\kappa \mathrm{B}$ p 65 in gastric tissue are shown in Figures 6 and 8. The expression of TNF- $\alpha$ and NF- $\kappa$ B p65 in the TFA group was significantly lower than that in the model group, especially in the high-dose group $(p<0.001)$. The results suggested that 


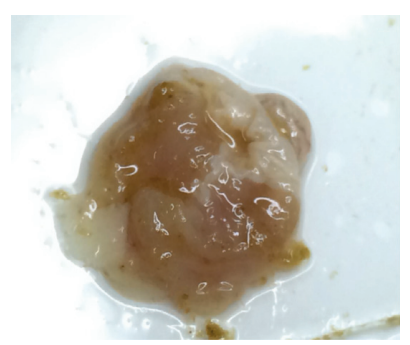

(a)

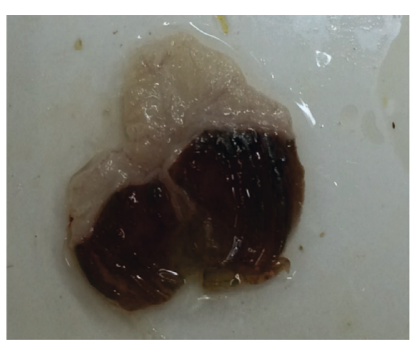

(b)

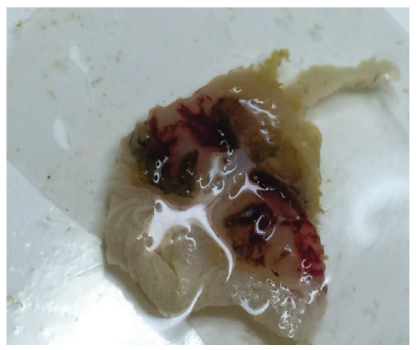

(e)

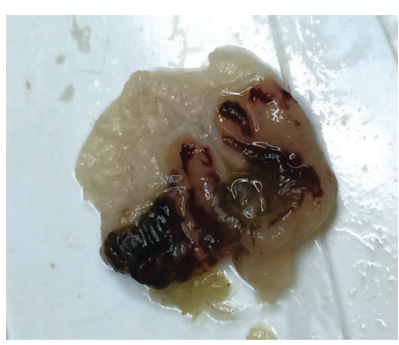

(c)

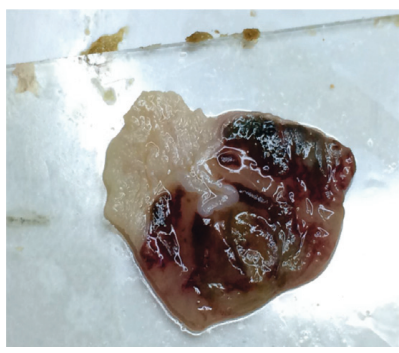

(f)

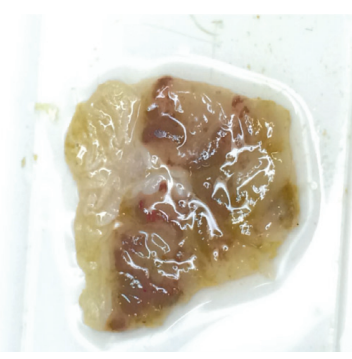

(d)

Figure 2: The gastric mucosal injury in mice $(n=10)$. (a) Control group; (b) model group; (c) omeprazole group; (d) high-dose group; (e) middle-dose group; (f) low-dose group.

TABLE 1: Ulcer index and inhibition rate of ulceration (Mean \pm SD, $n=10)$.

\begin{tabular}{lccc}
\hline Groups & $\begin{array}{c}\text { Dose } \\
(\mathrm{mg} / \mathrm{kg})\end{array}$ & Ulcer index & $\begin{array}{c}\text { Inhibition } \\
\text { ration }(\%)\end{array}$ \\
\hline Control & - & - & - \\
Model & - & $41.10+18.28$ & - \\
Omeprazole & 100 & $28.30+5.83$ & 31.14 \\
High-dose & 1200 & $13.40+8.60^{* * *}$ & 66.91 \\
Midium-dose & 600 & $24.10+12.10^{*}$ & 42.09 \\
Low-dose & 300 & $40.30+17.84$ & 1.95 \\
\hline
\end{tabular}

Note. ${ }^{*} p<0.05,{ }^{* *} p<0.01,{ }^{* * *} p<0.001$ vs. model group.

TFA could significantly downregulate the expression of inflammation-related proteins in the gastric tissue of gastric ulcer mice.

\section{Discussion}

In the present study, the model of ethanol-induced gastric ulcer was used to evaluate the gastroprotective activity of TFA. Ethanol is widely used in experimental gastric ulcer models because of its disadvantages. The model is simple and repeatable. The morphology, histological features, healing, and recurrence processes of ulcer are similar to human [22]. The severity of gastric injury was determined by ulcer index, and we found that TFA could inhibit the occurrence of ulcers and reduce the area of ulceration. It was shown by $\mathrm{HE}$ staining that TFA could relieve the pathological changes of gastric ulcer tissue in mice.

Oxidative stress is an important etiological factor in the damaged gastric mucosa [3]. GSH is a major antioxidant by interaction with lipid hydroperoxides. The ulcerogenic activity is related to the tissue levels of GSH. Increase in the levels of GSH can inhibit gastric ulceration [23]. MDA is the end-product of lipid peroxidation, and it is also an important marker of oxidative damage. The increase in MDA content is associated with the necrosis and apoptosis of cells [24]. SOD can exert its effects by removing oxygen free radicals from the body [25]. Therefore, GSH, MDA, and SOD were measured in this study to evaluate oxidative stress levels. Through the detection of the abovementioned oxidative damage indicators, we found TFA can increase the activity of SOD, the concentration of GSH, and at the same time decrease the level of MDA in gastric tissue.

$\mathrm{Bcl}-2$ family proteins is a family of evolutionarily related proteins, which derives its name from B-cell lymphoma 2 [26]. There are a total of 25 genes in the Bcl-2 family known to date. Bcl-2 family proteins are pivotal regulators of apoptosis by controlling mitochondrial outer membrane permeabilization (MOMP) [27]. When the cell is stimulated by apoptotic signals, the structure of Bax changes, shifting from the cytoplasm to the mitochondrial membrane and recruiting an amount of Bax proteins to form a polymer. Then, the polymer is inserted into the outer mitochondrial membrane, causing formation of mitochondrial apoptosisinduced channel (MAC). CytC, AIF, and other proapoptotic proteins release into the cytoplasm via MAC, resulting in apoptotic cell death $[27,28]$. A heterodimer may be formed by the proapoptotic protein and the antiapoptotic protein, and the ratio of $\mathrm{Bax} / \mathrm{Bcl}-2$ in the dimer is directly related to the regulation of apoptosis [29]. TFA can significantly upregulate the expression of antiapoptosis protien Bcl-2 and downregulate the expression of proapoptosis factor Bax. Thus, the apoptosis of cell was prevented through downregulation of $\mathrm{Bax} / \mathrm{Bcl}-2$ ratio.

Increasing evidence suggests that inflammatory mediators may play a role in the development and progression of gastric ulcer. A lot of literature had reported that TNF- $\alpha$, the 


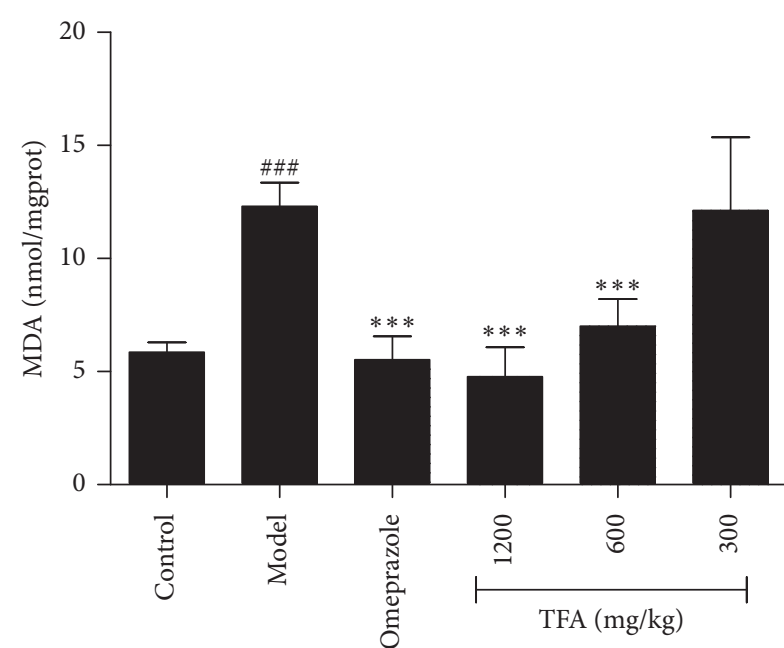

(a)

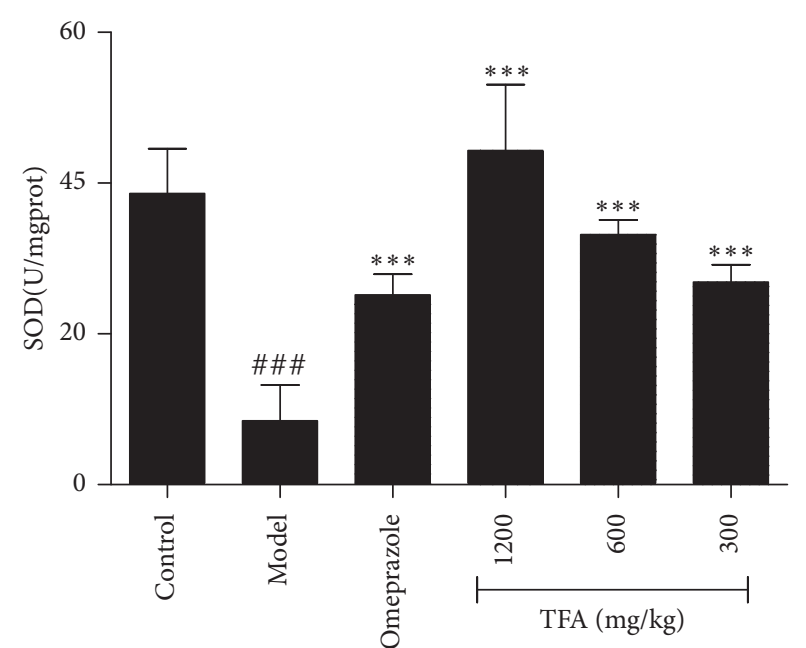

(b)

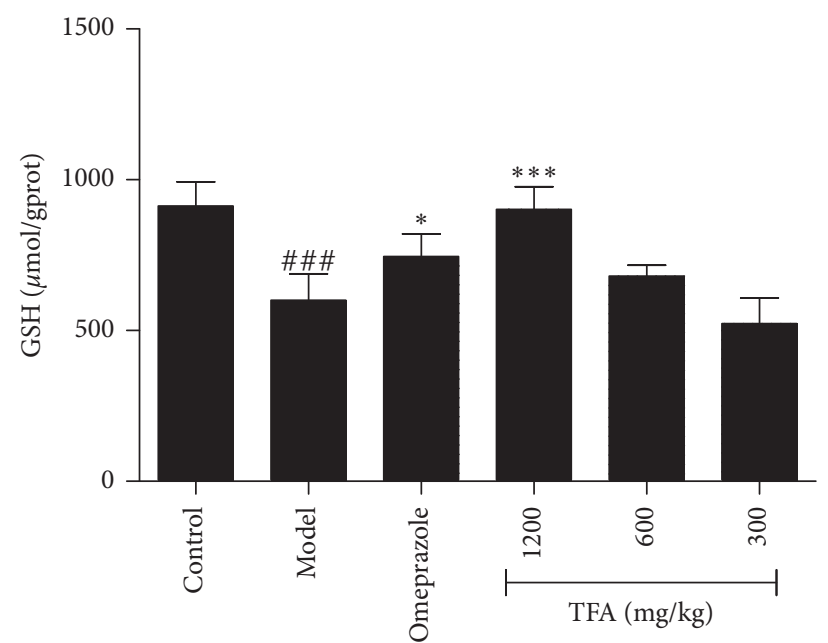

(c)

FIGURE 3: Effect of TFA on biochemical parameters of gastric tissue in mice with GU. (a) MDA levels of mice gastric tissue; (b) SOD activities of mice gastric tissue; and (c) GSH levels of mice gastric tissue (Mean $\pm \mathrm{SD}, n=6$ ) ${ }^{\# \# \#} p<0.001$ vs. control; ${ }^{*} p<0.05,{ }^{* *} p<0.01$, *** $p<0.001$ vs. model.

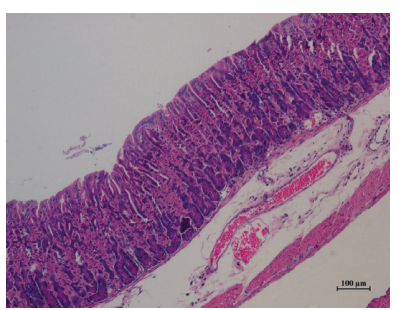

(a)

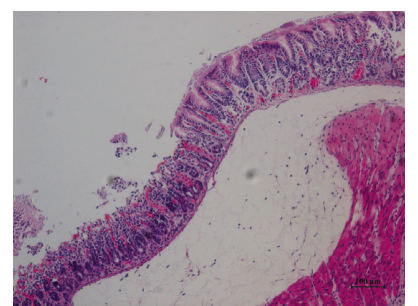

(b)

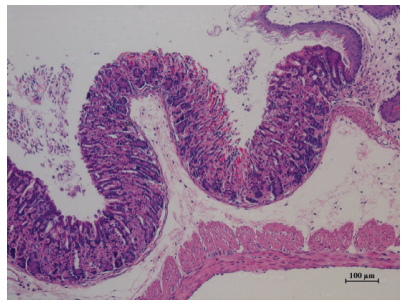

(e)

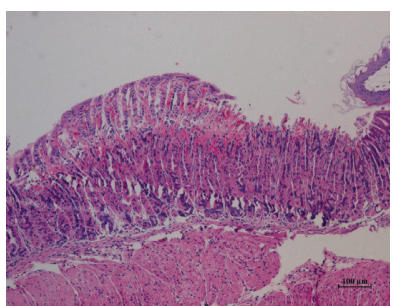

(c)

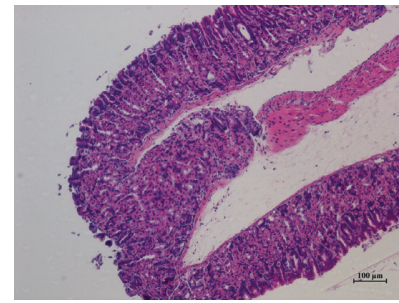

(f)

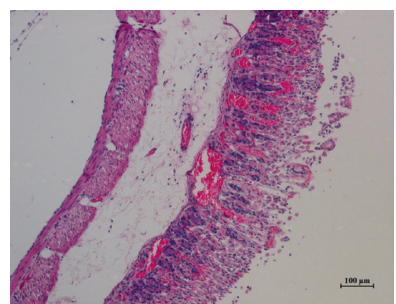

(d)

Figure 4: Histologic evaluations of gastric tissue (HE staining, $\times 100$ ). (a) Control group; (b) model group; (c) omeprazole group; (d) lowdose group; (e) middle-dose group; and (f) high-dose group. 


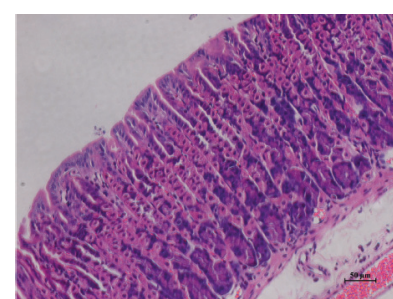

(a)

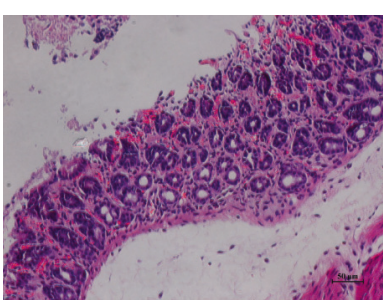

(b)

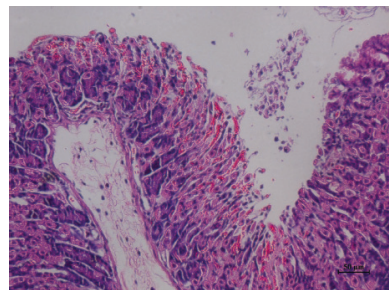

(e)

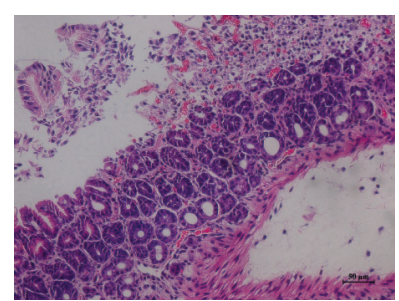

(c)

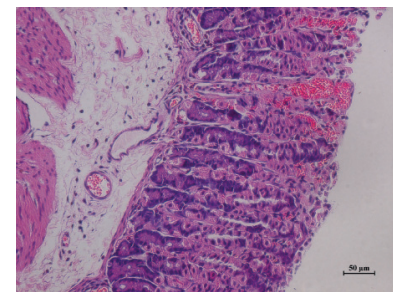

(f)

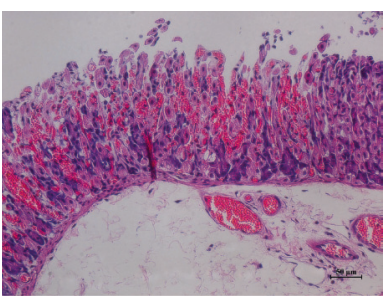

(d)

FIGURE 5: Histologic evaluations of gastric tissue (HE staining, $\times 200$ ). (a) Control group; (b) model group; (c) omeprazole group; (d) lowdose group; (e) middle-dose group; and (f) high-dose group.

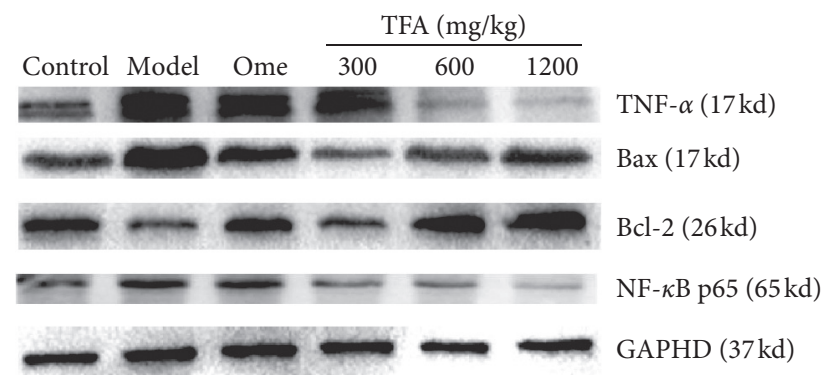

Figure 6: Expression of the proteins with western blot.

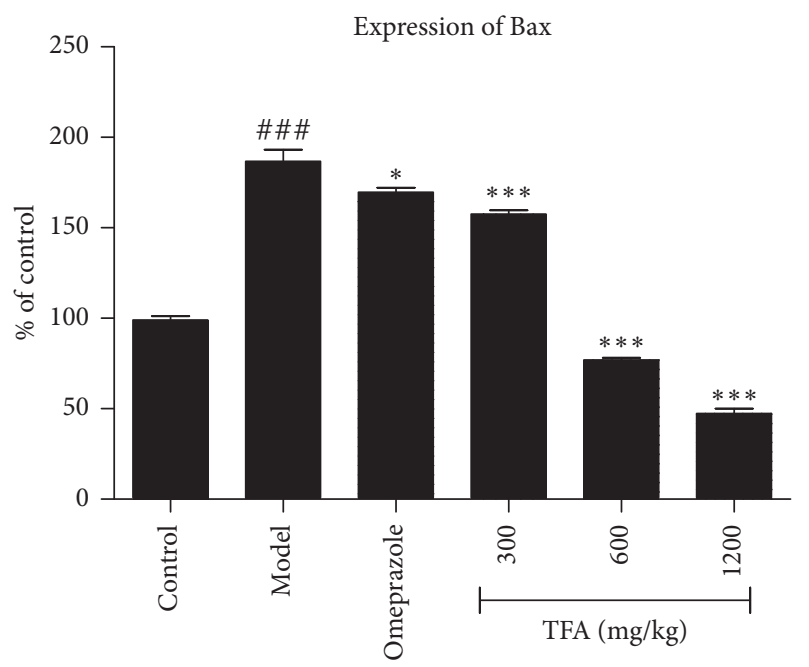

(a)

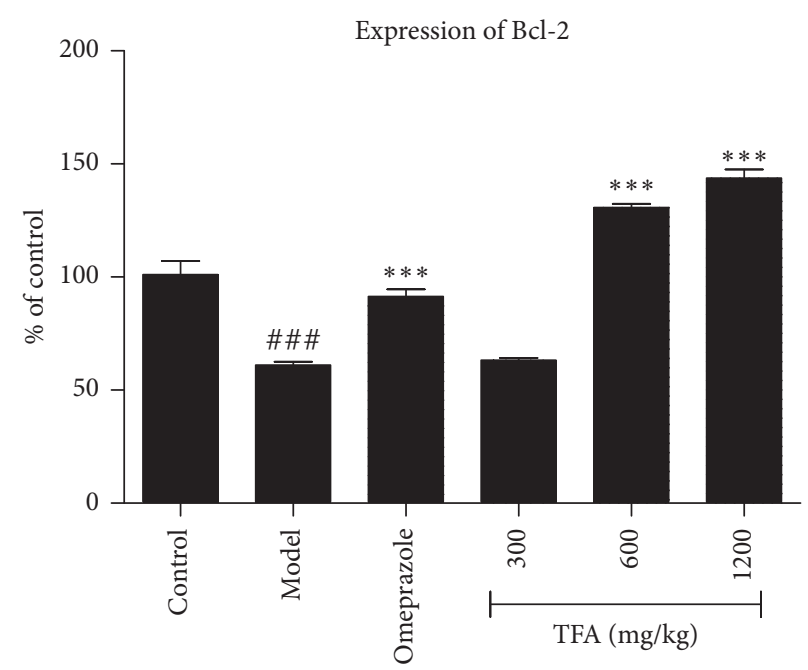

(b)

Figure 7: Continued. 


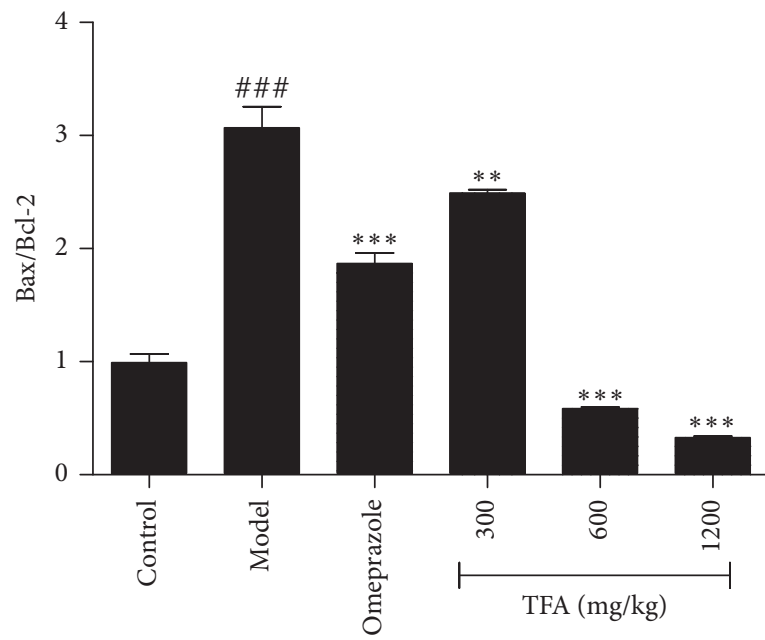

(c)

Figure 7: Analysis of Bax and Bcl-2 protein expression with western blot (Mean \pm SD). (a) Expression of Bax; (b) expression of Bcl-2; and (c) $\mathrm{Bax} / \mathrm{Bcl}-2{ }^{\# \# \#} p<0.001$ vs. control group; ${ }^{*} p<0.05,{ }^{* *} p<0.01,{ }^{* * *} p<0.001$ vs. model group.

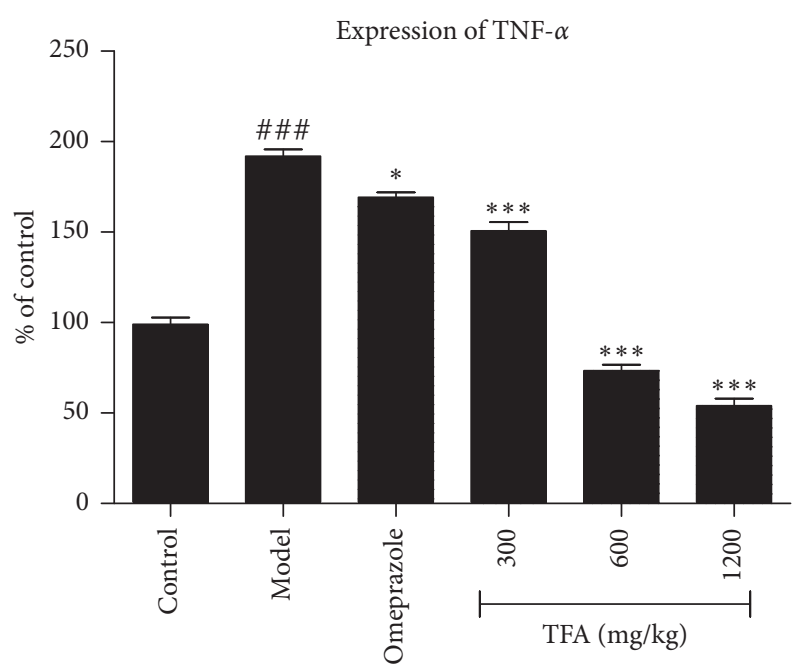

(a)

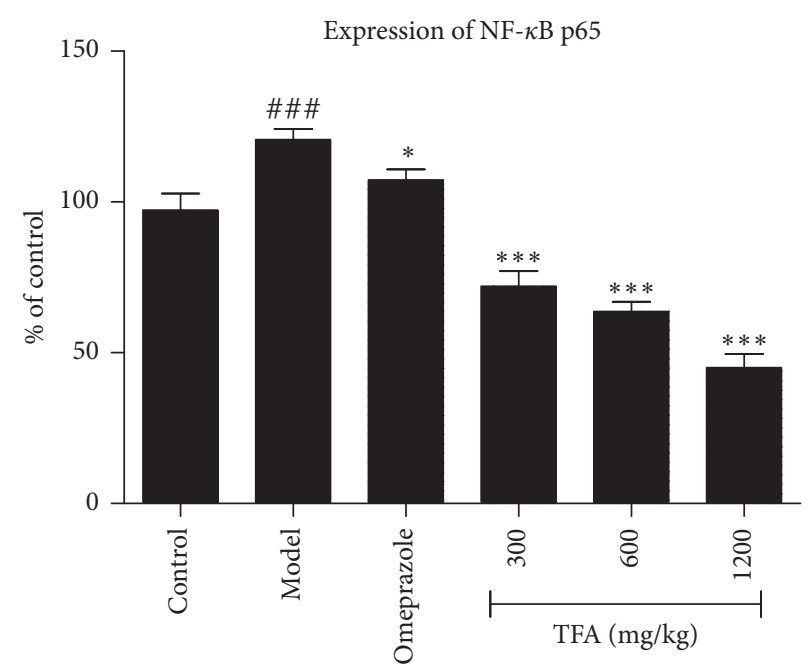

(b)

Figure 8: Analysis of TNF- $\alpha$ and NF- $\kappa$ B p65 protein expression with Western blot (Mean \pm SD). (a) expression of TNF- $\alpha$ (b) expression of NF- $\kappa$ B p $65{ }^{\# \# \#} p<0.001$ vs. control group; ${ }^{*} p<0.05,{ }^{* *} p<0.01,{ }^{* * *} p<0.001$ vs. model group.

main proinflammatory cytokine, was the important contributing factor in intestinal mucosal injury $[9,30]$. TNF- $\alpha$ is the initiator of the exogenous death pathway. It can combine with autologous, proximate, or distant cell membrane death receptor (TNFR). The initiation of the death receptor pathway leads to apoptosis (activated caspase-8), programmed necrosis (via RIP1 and RIP3), or inflammation (via $\mathrm{NF}-\kappa \mathrm{B}$ ) responses. NF- $\kappa \mathrm{B}$, a classic proinflammatory transcription factor, is kept inactive in resting cells by binding with a member of the IKB $\alpha$ inhibitor protein family [31]. NF- $\kappa \mathrm{B}$ is an ideal target for the mediation of proinflammatory factor expression in gastric ulcer [32]. Many natural products that have been promoted to have antiinflammatory activity have also been shown to inhibit NF$\kappa \mathrm{B}$. In the current study, western blot analysis indicated the significant downregulation of TNF- $\alpha$ and NF- $\kappa \mathrm{B}$ p65 expressions in the gastric tissue, which evidenced the antiinflammatory effect of TFA.

In summary, the present study suggested that TFA could significantly attenuate ethanol-induced gastric injury via antioxidative, anti-inflammatory, and antiapoptotic effects. Our data reinforced the therapeutic potential of TFA in the management of gastric ulcer.

\section{Data Availability}

The data used to support the findings of this study are included within the article.

\section{Conflicts of Interest}

The authors declare that there are no conflicts of interest regarding the publication of this article. 


\section{References}

[1] A. S. Tarnawski, "Increased susceptibility of aging gastric mucosa to injury: the mechanisms and clinical implications," World Journal of Gastroenterology, vol. 20, no. 16, p. 4467, 2014.

[2] A. M. S. Gomaa, N. A. Abd El-Mottaleb, and H. A. Aamer, "Antioxidant and anti-inflammatory activities of alpha lipoic acid protect against indomethacin-induced gastric ulcer in rats," Biomedicine \& Pharmacotherapy, vol. 101, pp. 188-194, 2018.

[3] S. Palle, A. Kanakalatha, and C. N. Kavitha, "Gastroprotective and antiulcer effects of Celastrus paniculatus seed oil against several gastric ulcer models in rats," Journal of Dietary Supplements, vol. 15, no. 4, pp. 373-385, 2017.

[4] Y. Yang, B. Yin, L. Lv et al., "Gastroprotective effect of aucubin against ethanol-induced gastric mucosal injury in mice," Life Sciences, vol. 189, pp. 44-51, 2017.

[5] R. H. Hunt, M. Camilleri, S. E. Crowe et al., "The stomach in health and disease," Gut, vol. 64, no. 10, pp. 1650-1668, 2015.

[6] M. Akanda, I.-S. Kim, D. Ahn et al., "Anti-inflammatory and gastroprotective roles of rabdosia inflexa through downregulation of pro-inflammatory cytokines and MAPK/NF- $\kappa \mathrm{B}$ signaling pathways," International Journal of Molecular Sciences, vol. 19, no. 2, p. 584, 2018.

[7] J. Yoo, J. Lee, Y. Lee et al., "Protective effect of bovine milk against $\mathrm{HCl}$ and ethanol-induced gastric ulcer in mice," Journal of Dairy Science, vol. 101, no. 5, pp. 3758-3770, 2018.

[8] H. Bernstein, C. Bernstein, C. Payne, K. Dvorakova, and H. Garewal, "Bile acids as carcinogens in human gastrointestinal cancers," Mutation Research/Reviews in Mutation Research, vol. 589, no. 1, pp. 47-65, 2005.

[9] W. Li, X. Wang, W. Zhi et al., "The gastroprotective effect of nobiletin against ethanol-induced acute gastric lesions in mice: impact on oxidative stress and inflammation," Immunopharmacology and Immunotoxicology, vol. 39, no. 6, pp. 354-363, 2017.

[10] E. Mohamed, I. Abu Hashim, R. Yusif et al., "Polymeric micelles for potentiated antiulcer and anticancer activities of naringin," International Journal of Nanomedicine, vol. 13, pp. 1009-1027, 2018.

[11] W.-P. Bi, H. Man, and M. Man, "Efficacy and safety of herbal medicines in treating gastric ulcer: a review," World Journal of Gastroenterology, vol. 20, no. 45, pp. 17020-17028, 2014.

[12] X.-X. Pan, J.-H. Tao, S. Jiang, Y. Zhu, D.-W. Qian, and J.-A. Duan, "Characterization and immunomodulatory activity of polysaccharides from the stems and leaves of Abelmoschus manihot and a sulfated derivative," International Journal of Biological Macromolecules, vol. 107, pp. 9-16, 2018.

[13] G. Ai, Q. Liu, W. Hua, Z. Huang, and D. Wang, "Hepatoprotective evaluation of the total flavonoids extracted from flowers of Abelmoschus manihot (L.) Medic: in vitro and in vivo studies," Journal of Ethnopharmacology, vol. 146, no. 3, pp. 794-802, 2013.

[14] D. Lv, X. Cheng, L. Tang, and M. Jiang, "The cardioprotective effect of total flavonoids on myocardial ischemia/reperfusion in rats," Biomedicine \& Pharmacotherapy, vol. 88, pp. 277-284, 2017.

[15] C. Xue, S. Jiang, J. Guo, D. Qian, J.-a. Duan, and E. Shang, "Screening for in vitro metabolites of Abelmoschus manihot extract in intestinal bacteria by ultra-performance liquid chromatography/quadrupole time-of-flight mass spectrometry," Journal of Chromatography B, vol. 879, no. 32, pp. 3901-3908, 2011.

[16] C. Xue, J. Guo, D. Qian et al., "Identification of the potential active components of Abelmoschus manihot in rat blood and kidney tissue by microdialysis combined with ultra- performance liquid chromatography/quadrupole time-offlight mass spectrometry," Journal of Chromatography $B$, vol. 879, no. 5-6, pp. 317-325, 2011.

[17] J. Li, J. Gong, L. Zhao, H. Zou, and Y. Yan, "Extraction process of total flavonoids of Abelmoschus manihot," Journal of International Pharmaceutical Research, vol. 43, no. 2, pp. 370-373, 2016.

[18] X.-x Lv and Z.-1. Chen, "Improvement of determination method of flower of sunset Abelmoschus in Chinese pharmacopoeia (2010 edition)," Strait Pharmaceutical, vol. 27, no. 10, pp. 67-69, 2015.

[19] D. Hollander, A. Tarnawski, W. J. Krause, and H. Gergely, "Protective effect of sucralfate against alcohol-induced gastric mucosal injury in the rat," Gastroenterology, vol. 88 , no. 1 , pp. 366-374, 1985.

[20] P. H. Guth, D. Aures, and G. Paulsen, "Topical aspirin plus $\mathrm{HCl}$ gastric lesions in the rat," Gastroenterology, vol. 76, no. 1, pp. 88-93, 1979.

[21] I. Szelenyi and K. Thiemer, "Distention ulcer as a model for testing of drugs for ulcerogenic side effects," Archives of Toxicology, vol. 41, no. 1, pp. 99-105, 1978.

[22] W. XIAO, A. XU, and J. Hui, "Advances in models of gastric ulceration," Pharmaceutical and Clinical Research, vol. 24, no. 2, pp. 145-150, 2016.

[23] A. P. Jayaraj, K. R. Rees, F. I. Tovey et al., "A molecular basis of peptic ulceration due to diet," British Journal of Experimental Pathology, vol. 67, no. 1, pp. 149-155, 1986.

[24] M. Xie, H. Chen, S. Nie, W. Tong, J. Yin, and M. Xie, "Gastroprotective effect of gamma-aminobutyric acid against ethanol-induced gastric mucosal injury," Chemico-Biological Interactions, vol. 272, pp. 125-134, 2017.

[25] J.-W. Song, C.-S. Seo, T.-I. Kim et al., "Protective effects of manassantin a against ethanol-induced gastric injury in rats," Biological \& Pharmaceutical Bulletin, vol. 39, no. 2, pp. 221229, 2016.

[26] A. R. D. Delbridge, S. Grabow, A. Strasser, and D. L. Vaux, "Thirty years of BCL-2: translating cell death discoveries into novel cancer therapies," Nature Reviews Cancer, vol. 16, no. 2, pp. 99-109, 2016.

[27] V. Andreu-Fernández, M. Sancho, A. Genovés et al., "Bax transmembrane domain interacts with prosurvival Bcl-2 proteins in biological membranes," Proceedings of the $\mathrm{Na}$ tional Academy of Sciences, vol. 114, no. 2, pp. 310-315, 2017.

[28] A. Ashkenazi, W. J. Fairbrother, J. D. Leverson, and A. J. Souers, "From basic apoptosis discoveries to advanced selective Bcl-2 family inhibitors," Nature Reviews Drug Discovery, vol. 16, no. 4, pp. 273-284, 2017.

[29] S. Thangarajan, A. Vedagiri, S. Somasundaram, R. Sakthimanogaran, and M. Murugesan, "Neuroprotective effect of morin on lead acetate- induced apoptosis by preventing cytochrome $\mathrm{c}$ translocation via regulation of $\mathrm{Bax} / \mathrm{Bcl}-$ 2 ratio," Neurotoxicology and Teratology, vol. 66, pp. 35-45, 2018.

[30] R. Kamel, E. M. El Morsy, and A. S. Awad, "Immunomodulatory effect of candesartan on indomethacin-induced gastric ulcer in rats," Immunopharmacology and Immunotoxicology, vol. 34, no. 6, pp. 956-961, 2012.

[31] B. Sun, Q. Xia, and Z. Gao, "Total flavones of choerospondias axillaris attenuate cardiac dysfunction and myocardial interstitial fibrosis by modulating NF- $\kappa \mathrm{B}$ signaling pathway," Cardiovascular Toxicology, vol. 15, no. 3, pp. 283-289, 2015.

[32] X. Chang, F. Luo, W. Jiang et al., "Protective activity of salidroside against ethanol-induced gastric ulcer via the MAPK/NF- $\kappa \mathrm{B}$ pathway in vivo and in vitro," International Immunopharmacology, vol. 28, no. 1, pp. 604-615, 2015. 